\title{
Advances in the Diagnosis and Treatment of Tuberculosis
}

\author{
Payam Nahid*, Madhukar Pai*, and Philip C. Hopewell \\ Division of Pulmonary and Critical Care Medicine, San Francisco General Hospital, University of California at San Francisco, \\ San Francisco, California
}

\begin{abstract}
Although truly major advances that would revolutionize tuberculosis (TB) diagnosis and treatment have not been realized, we are beginning to see the innovations that have been prompted by the recognition of the economic potential of the market for new diagnostic tests and treatments for TB and considerably increased public and private funding. Despite the enormous global burden of TB and the overall low rates of case detection worldwide, conventional approaches to diagnosis have, until recently, relied on tests that have major limitations. In this review of advances in diagnosis, we focus on strengths and limitations of newer tests that are available for the diagnosis of latent and active tuberculosis and rapid detection of drug resistance, specifically, tests that measure release of IFN- $\gamma$ in response to stimulation by Mycobacterium tuberculosis antigens, nucleic acid amplification for identification of $M$. tuberculosis complex, and rapid tests for detecting drug resistance. Standard regimens for treating TB have not changed for more than $30 \mathrm{yr}$ and still require a minimum of 6 mo to have a high likelihood of a lasting cure. In this article, we focus on important changes in the philosophy of treatment, emphasizing the responsibility of the provider to assure successful completion of treatment, and on the roles of existing anti-TB agents and newer drugs such as rifabutin, rifapentine, and fluoroquinolones.
\end{abstract}

Keywords: diagnosis; latent tuberculosis infection; treatment; tuberculosis

After many years of scientific quiescence, tuberculosis (TB) research has undergone a renaissance. Although truly major advances that would revolutionize TB diagnosis, treatment, and prevention have not been realized, we are beginning to see the innovations that have been prompted by the recognition of the economic potential of the market for new diagnostic tests and treatments for TB and considerably increased public and private funding. Current initiatives targeting the development of (or in some cases, better application of) new diagnostic tests, new drugs, and new vaccines have increased the pace of identification and testing of a number of potentially useful innovations (1-3).

In this article, we focus on strengths and limitations of newer tests that are available for the diagnosis of latent TB infection (LTBI), active TB, and rapid detection of drug resistance. With regard to treatment, we focus on important changes in the philosophy of treatment, emphasizing the responsibility of the provider to assure successful completion of treatment, and on the roles

(Received in original form November 15, 2005; accepted in final form November 21, 2005) Supported in part by the National Institutes of Health, NIH/NIAID grant R01 Al 34238. This funding source had no role in the preparation, review, or approval of the manuscript.

*These investigators contributed equally to this article.

Correspondence and requests for reprints should be addressed to Philip C. Hopewell, M.D., Division of Pulmonary and Critical Care Medicine, San Francisco General Hospital, University of California, San Francisco, 1001 Potrero Avenue, Room 5K1, San Francisco, CA 94110. E-mail: phopewell@medsfgh.ucsf.edu

Proc Am Thorac Soc Vol 3. pp 103-110, 2006

DOI: 10.1513/pats.200511-119jH

Internet address: www.atsjournals.org of existing anti-TB agents and newer drugs such as rifabutin, rifapentine, and fluoroquinolones.

\section{NEW APPROACHES TO DIAGNOSIS}

Accurate and early diagnosis of TB is crucial to effective patient management and to TB control. Moreover, accurate identification of LTBI is the key to prevention of the disease among persons at risk. Despite the enormous global burden of TB and the overall low rates of case detection, conventional approaches to diagnosis continue to rely on tests that have major drawbacks. For example, sputum smear microscopy is insensitive; culture is technically complex and slow; determination of drug susceptibility is even more technically complex and slower yet; chest radiography is nonspecific; and tuberculin skin testing is imprecise, and the results are often nonspecific. In view of these limitations, there is a need for less complicated and more accurate tests. We may be on the verge of major technical breakthroughs that will lead to improved diagnostic tests. In this article we focus on strengths and limitations of newer tests that are available for the diagnosis of LTBI, active TB, and rapid detection of drug resistance.

\section{Latent TB Infection}

The tuberculin skin test (TST) was, until recently, the only tool available for detecting LTBI. Although the TST has proven to be useful in clinical practice, it has several major limitations (4). Thanks to advances in immunology and genomics, an alternative has emerged in the form of a family of T-cell-based in vitro assays that detect IFN- $\gamma(5-8)$. These assays detect cellular immune response by measuring IFN- $\gamma$ released by $\mathrm{T}$ cells after stimulation by Mycobacterium tuberculosis antigens. Early versions of IFN- $\gamma$ assays used purified protein derivative (PPD) as the stimulating antigen, but these tests have been replaced by newer versions that use antigens (early secreted antigen target-6 [ESAT-6] and culture filtrate protein-10 [CFP-10]) that are substantially more specific for $M$. tuberculosis than PPD. These proteins, encoded by genes located within the region of difference 1 (RD1) segment of the M. tuberculosis genome, are more specific for M. tuberculosis than PPD because they are not shared with the bacillus Calmette-Guérin (BCG) vaccine strains or certain nontuberculous mycobacterial species of clinical relevance.

Two IFN- $\gamma$ assays, based on RD1 antigens, are available as commercial kits: the QuantiFERON-TB Gold (Cellestis Ltd., Carnegie, Australia) assay and the T SPOT-TB (Oxford Immunotec, Oxford, UK). The QuantiFERON-TB Gold assay is a whole-blood, ELISA-based test, whereas the T SPOT-TB test uses peripheral blood mononuclear cells and ELISPOT technology. The QuantiFERON-TB Gold assay comes in two formats: a 24-well culture plate format (used in the United States and approved by the U.S. Food and Drug Administration [FDA]) and a newer, simplified, in-tube format (not FDA approved). The T SPOT-TB test is CE marked for use in Europe and is awaiting FDA approval.

Current evidence, reviewed extensively elsewhere (5-10), on the performance of IFN- $\gamma$ assays suggests that RD1-based IFN- $\gamma$ 
assays have higher specificity, better correlation with surrogate measures of exposure to M. tuberculosis, and less cross-reactivity due to BCG vaccination than the TST. RD1-based IFN- $\gamma$ assays that use a mixture of ESAT- 6 and CFP-10 seem to be at least as sensitive as the PPD-based TST in active TB (Table 1). Other potential advantages include convenience; avoidance of the subjectivity inherent in measurements of cutaneous induration produced by the TST; the need for only one patient visit; and the ability to perform repeat testing without boosting the response, as may occur with serial tuberculin testing.

Because of their higher specificity, IFN- $\gamma$ assays may be helpful in low-prevalence, resource-rich settings where crossreactivity due to BCG may pose difficulties in TST interpretation. In such settings, IFN- $\gamma$ assays are likely to reduce falsepositive results and enhance the efficiency of targeted LTBI screening and consequently LTBI treatment.*

Although poorly studied, another potential application of IFN- $\gamma$ assays is serial testing of health care workers. In such populations, the RD1-based IFN- $\gamma$ assays will eliminate the need for repeat visits, avoid boosting and thus eliminate the need for two-step TST testing at baseline, and may minimize interpretational difficulties that often hamper serial tuberculin testing programs.

Despite the growing body of evidence supporting the use of IFN- $\gamma$ assays, several unresolved issues remain $(5,7)$, and ongoing studies should help to define the role of these assays in clinical practice. Several studies have shown unexplained discordance between TST and IFN- $\gamma$ assay results $(5,7)$. Further research is needed to determine the biological basis for this phenomenon. There is weak evidence on the role and utility of these assays in several patient subgroups, including immunocompromised individuals (including those with HIV/AIDS), patients with extrapulmonary TB, children, and populations in high-incidence countries $(5,7)$. In immunocompromised individuals, IFN- $\gamma$ assays might have a higher proportion of indeterminate results, and this may indicate underlying anergy $(11,12)$. Few published studies exist on the long-term reproducibility of these assays, particularly in serial testing situations (e.g., health care worker screening where boosting, conversions, and reversions are known to occur). The impact of anti-TB treatment on IFN- $\gamma$ assay responses is under investigation, and it is not clear if these tests can be used for monitoring LTBI and active TB treatment (5). The impact of nontuberculous mycobacterial exposure and $M$. leprae infection on IFN- $\gamma$ assay results is poorly defined and deserves further study. Although there is limited evidence, based on one small study (13) of an association between IFN- $\gamma$ response to ESAT-6 and subsequent progression to active TB among contacts of patients with $\mathrm{TB}$, the association between positive IFN- $\gamma$ responses and long-term progression to active disease is largely unknown. Finally, one limitation of IFN- $\gamma$ assays, particularly for high-burden countries, is their higher material costs and the need for laboratory infrastructure and support. However, the benefits of a more specific, convenient blood test might balance the higher materials and laboratory costs. Cost-effectiveness studies are therefore needed to better appreciate the role of IFN- $\gamma$ assays in clinical and public health settings (10).

\section{Diagnosis of TB}

Nucleic acid amplification (NAA) tests amplify target nucleic acid regions that uniquely identify the $M$. tuberculosis complex. Because NAA tests can be directly used on clinical specimens (such as sputum), they are also called "direct amplification tests." NAA tests are categorized as commercial kits or in-house assays. Commercial kits include the Amplicor MTB tests (Roche Diagnostic Systems, Branchburg, NJ), the Amplified Mycobacterium tuberculosis Direct Test (MTD) (Gen-Probe, Inc., San Diego, $\mathrm{CA}$ ), and the BD ProbeTec ET assay (Becton Dickinson Biosciences, Sparks, MD). The Amplicor and MTD tests are FDA

TABLE 1. SUMMARY OF EVIDENCE ON THE PERFORMANCE AND OPERATIONAL CHARACTERISTICS OF TUBERCULIN SKIN TEST AND RD1-BASED IFN- $\gamma$ ASSAYS

\begin{tabular}{|c|c|c|}
\hline Performance and Operational Characteristics & TST & RD1-based IFN- $\gamma$ Assays \\
\hline Estimated sensitivity (in patients with active TB) & $\begin{array}{l}\text { 75-90 \% } \\
\text { (lower in immunocompromised } \\
\text { populations) }\end{array}$ & $\begin{array}{l}\text { 80-95\% } \\
\text { (inadequate data in } \\
\text { immunocompromised populations) }\end{array}$ \\
\hline $\begin{array}{l}\text { Estimated specificity (in healthy individuals } \\
\text { with no known TB disease/exposure) }\end{array}$ & $\begin{array}{l}\text { 70-95\% } \\
\quad \text { (lower in BCG vaccinated) }\end{array}$ & $\begin{array}{l}\text { 95-100\% } \\
\quad \text { (unchanged with BCG) }\end{array}$ \\
\hline Cross-reactivity with BCG & Yes & Less likely \\
\hline $\begin{array}{l}\text { Cross-reactivity with nontuberculous } \\
\text { mycobacteria }\end{array}$ & Yes & Less likely \\
\hline $\begin{array}{l}\text { Association between test-positivity and } \\
\text { subsequent risk of active TB during follow-up }\end{array}$ & $\begin{array}{l}\text { Moderate to strong positive } \\
\text { association }\end{array}$ & Insufficient evidence \\
\hline Correlation with $M$. tuberculosis exposure & Yes & $\begin{array}{l}\text { Yes (correlated better with exposure } \\
\text { than TST in some head-to-head } \\
\text { comparisons) }\end{array}$ \\
\hline $\begin{array}{l}\text { Benefits of treating test-positives (based on } \\
\text { randomized controlled trials) }\end{array}$ & Yes & No evidence \\
\hline Reliability (reproducibility) & Moderate & Limited evidence but may be high \\
\hline Boosting phenomenon & Yes & No \\
\hline Adverse reactions & Rare & Rare \\
\hline Material costs & Low & Moderate to high \\
\hline Patient visits & Two & One \\
\hline Laboratory infrastructure required & No & Yes \\
\hline Time to obtain a result & $2-3 d$ & $1-2 \mathrm{~d}$, but longer if run as batches \\
\hline Trained personnel required & Yes & Yes \\
\hline
\end{tabular}

Definition of abbreviations: BCG = bacillus Calmette-Guérin; TB = tuberculosis; TST = tuberculin skin test.

Adapted by permission from Reference 7.

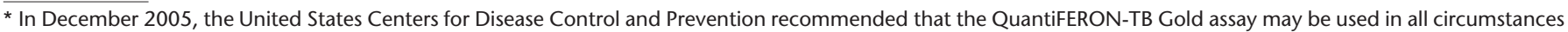
in which the TST is currently used. http://www.cdc.gov/mmwr/previews/mmwrhtml/rr5415a4.html. 
TABLE 2. RESULTS OF RECENT META-ANALYSES AND SYSTEMATIC REVIEWS ON THE ACCURACY OF NUCLEIC ACID AMPLIFICATION TESTS FOR TUBERCULOSIS

\begin{tabular}{|c|c|c|c|c|c|}
\hline $\begin{array}{l}\text { Meta-Analysis/ } \\
\text { Systematic } \\
\text { Review (year, } \\
\text { reference) }\end{array}$ & $\begin{array}{l}\text { No.Studies } \\
\text { Included in } \\
\text { the Review }\end{array}$ & Type of TB & Type of NAA Tests & $\begin{array}{c}\text { Principal Findings about the } \\
\text { Accuracy of NAA tests }\end{array}$ & Conclusions \\
\hline $\begin{array}{l}\text { Flores and } \\
\text { colleagues } \\
\text { (2005) (16) }\end{array}$ & 84 & Pulmonary TB & In-house PCR & $\begin{array}{l}\text { Highly variable sensitivity and } \\
\text { specificity estimates; } \\
\text { sensitivity lower than } \\
\text { specificity }\end{array}$ & $\begin{array}{l}\text { Estimates of accuracy of in-house tests } \\
\text { were highly inconsistent. The use of } \\
\text { IS6110 as an amplification target and } \\
\text { the use of nested PCR methods were } \\
\text { associated with higher accuracy. }\end{array}$ \\
\hline $\begin{array}{l}\text { Sarmiento and } \\
\text { colleagues } \\
(2003)(20)\end{array}$ & 50 & $\begin{array}{l}\text { Smear-negative } \\
\text { pulmonary TB }\end{array}$ & $\begin{array}{l}\text { Commercial tests } \\
\text { and in-house PCR }\end{array}$ & $\begin{array}{l}\text { Highly variable sensitivity and } \\
\text { specificity estimates; } \\
\text { sensitivity lower than } \\
\text { specificity }\end{array}$ & $\begin{array}{l}\text { Not consistently accurate enough to be } \\
\text { routinely recommended for the } \\
\text { diagnosis of smear-negative } \\
\text { pulmonary TB }\end{array}$ \\
\hline $\begin{array}{l}\text { Pai and colleagues } \\
\text { (2004) (17) }\end{array}$ & 40 & TB pleuritis & $\begin{array}{l}\text { Commercial tests } \\
\text { and in-house PCR }\end{array}$ & $\begin{array}{l}\text { High specificity; sensitivity was } \\
\text { lower and variable }\end{array}$ & $\begin{array}{l}\text { Commercial NAA tests may have a } \\
\text { potential role in ruling in TB pleuritis. } \\
\text { However, these tests have low and } \\
\text { variable sensitivity and may not be } \\
\text { useful in ruling out the disease. Clinical } \\
\text { applicability of in-house tests is unclear } \\
\text { because of inconsistent results } \\
\text { from various studies. }\end{array}$ \\
\hline $\begin{array}{l}\text { Piersimoni and } \\
\text { Scarparo } \\
(2003)(19)\end{array}$ & $>40$ & $\begin{array}{l}\text { Pulmonary and } \\
\text { extrapulmonary } \\
\text { TB }\end{array}$ & Commercial tests & $\begin{array}{l}\text { High specificity; sensitivity was } \\
\text { lower and variable }\end{array}$ & $\begin{array}{l}\text { NAA tests have to be performed in } \\
\text { conjunction with smears/cultures. } \\
\text { Clinical value depends on pre-test } \\
\text { probability. }\end{array}$ \\
\hline $\begin{array}{l}\text { Pai and colleagues } \\
\text { (2003) (18) }\end{array}$ & 49 & TBM & $\begin{array}{l}\text { Commercial tests } \\
\text { and in-house PCR }\end{array}$ & $\begin{array}{l}\text { High specificity; sensitivity was } \\
\text { lower and variable }\end{array}$ & $\begin{array}{l}\text { Commercial NAA tests have a potential } \\
\text { role in confirming TBM, although their } \\
\text { overall low sensitivity precludes the use } \\
\text { of these tests to rule out TBM. Clinical } \\
\text { applicability of in-house tests is unclear } \\
\text { because of inconsistent results from } \\
\text { various studies. }\end{array}$ \\
\hline
\end{tabular}

Definition of abbreviations: NAA = nucleic acid amplification; PCR = polymerase chain reaction; $\mathrm{TB}=$ tuberculosis; $\mathrm{TBM}=$ tuberculosis meningitis.

Adapted by permission from Reference 14 .

approved. In-house tests are laboratory-developed polymerase chain reaction (PCR) assays; they vary greatly in their design and laboratory methods.

The accuracy and reliability of NAA tests for TB have been extensively studied and reviewed $(9,14,15)$. Table 2 presents the summary results of several recent meta-analyses and reviews (16-20) on the accuracy of NAA tests. The overwhelming majority of the studies on NAA tests reported very high estimates of specificity for pulmonary and extrapulmonary TB. Sensitivity estimates have been lower and highly variable across studies. Sensitivity estimates have been lower in paucibacillary forms of TB (smear-negative pulmonary TB and extrapulmonary TB). In contrast, the sensitivity of NAA tests has been maximal in smear-positive pulmonary TB. In general, the results of in-house PCR evaluations have been more inconsistent than commercial tests. In-house PCR tests, therefore, have limited clinical applicability. Commercial assays are standardized and produce results that are more consistent.

The current evidence (Table 2) suggests that NAA tests cannot replace conventional tests such as microscopy and culture; they should be used and interpreted in conjunction with conventional tests and clinical data. NAA tests, in general, have high specificity and positive predictive value, and these characteristics confer value in terms of their ability to rule in TB. A positive test in a patient with a reasonably high pretest probability is confirmatory of TB, particularly in patients with positive sputum smear microscopy. Therefore, NAA tests can be used to confirm that a positive sputum smear is due to M. tuberculosis (9). NAA tests, however, have relatively lower sensitivity and negative predictive value, particularly in patients with negative sputum smears and with extrapulmonary TB. A negative test, therefore, does not rule out the diagnosis of TB. Therefore, NAA tests should not be performed if sputum smears are negative and if the index of clinical suspicion is low. A negative NAA test in a patient with a high index of clinical suspicion should not preclude continued investigation. Because NAA tests amplify dead mycobacteria and cannot distinguish viable from nonviable bacilli, they should not be used in patients who are being treated. To ensure reliability, NAA tests should be performed only in laboratories that have appropriate quality assurance systems in place.

\section{Rapid Detection of Drug Resistance}

Molecular beacons. Molecular beacons are oligonucleotides that emit light when a chemical reaction occurs. Recently, a novel test that uses molecular beacons for the rapid detection of mutations associated with drug resistance have been developed (21-24). The test uses fluorescent-labeled, hair-pin-shaped DNA probes in which a fluorophore is adjacent to a molecule that quenches the light. In a real-time PCR assay, if the amplified PCR products have the normal, wild-type gene sequence, the DNA probe unfolds, resulting in detectable fluorescence. Resistant strains with mutations in the target sequence do not hybridize with the probe: The probe remains folded, and there is no fluorescence detected. Although few studies have evaluated molecular beacons, available data suggest that these tests have high sensitivity (89-98\%) and specificity (99-100\%) for the detection of rifampicin resistance (21-24). Sensitivity for the detection of isoniazid resistance is lower because of the multiplicity of mutations that may lead to resistance to isoniazid $(22,23)$. Molecular beacons are not available as commercial kits and are not FDA approved. They 
require sophisticated technology that limits their widespread use. Their use is mostly restricted to research and reference laboratories.

Line probe assays. Line probe assays are a family of novel DNA strip tests that use PCR and reverse hybridization methods for the rapid detection of drug resistance. Commercially available kits include the INNO-LiPA Rif. TB kit (Innogenetics, Gent, Belgium) and the GenoType MTBDR assay (Hain Lifescience, Nehren, Germany). These kits are not FDA approved. Line probe assays are designed to identify $M$. tuberculosis complex and to simultaneously detect genetic mutations related to drug resistance. The LiPA kit, for example, contains 10 oligonucleotide probes (one specific for the M. tuberculosis complex, five overlapping wild-type $\mathrm{S}$ probes, and four R probes for detecting specific mutations of resistant genotypes) immobilized on nitrocellulose paper strips. LiPA is performed by extracting DNA from cultures or directly from clinical samples and amplifying the rifampicin resistance-determining region of the rpoB gene using PCR. The PCR products are hybridized with the immobilized probes, and results are determined by colorimetric development.

A number of studies have evaluated the diagnostic accuracy of LiPA for detecting rifampicin resistance in several settings. The results of these studies have been summarized in a recent metaanalysis (25) that suggests that the LiPA assay is highly sensitive and specific for detecting rifampicin-resistant M. tuberculosis in culture and, to a slightly lesser degree, in clinical specimens. The majority of studies had sensitivity estimates of $95 \%$ or greater, and nearly all were $100 \%$ specific. There is a paucity of data on the application of this test directly to clinical specimens. If further studies indicate that line probe assays consistently and accurately detect rifampicin resistance when applied directly to clinical specimens, it could be a useful test in select patient populations in which drug resistance is strongly suspected. The GenoType MTBDR assay also may be promising (26) but requires further validation. In general, line probe assays are expensive and require sophisticated laboratory support.

Phage-based assays. Phage-based assays have been evaluated for the diagnosis of TB (27) and drug susceptibility testing (28). The technology uses mycobacteriophages to infect live M. tuberculosis and detect the bacilli using a phage amplification method or detection of light. In the former method, the underlying principle is amplification of phages after their infection of $M$. tuberculosis, followed by detection of progeny phages as plaques on a lawn of $M$. smegmatis. In the latter method, the principle is detection of light produced by luciferase reporter phages after their infection of live M. tuberculosis. Amplificationbased assays are commercially available, whereas luciferase reporter phage tests (e.g., Bronx box) are under development. In general, phage assays have a turnaround time of 48-72 $\mathrm{h}$ and require a laboratory infrastructure similar to that required for performing mycobacterial cultures.

Phage-based assays are available as commercial kits. For diagnosis, the FASTPlaque-TB (Biotec Laboratories Ltd., Ipswich, UK) assay can be directly used on sputum specimens. A variant, the FASTPlaque-TB-MDRi kit, is designed to detect rifampicin resistance in culture isolates. An advanced version of this kit, FASTPlaque-TB-Response, has been developed for the detection of drug resistance directly from sputum specimens. Drug resistance is diagnosed when $M$. tuberculosis is detected in samples that contain the drug (e.g., rifampicin). The FASTPlaque-TB kits are not FDA approved but are CE marked for use in Europe.

A recent meta-analysis summarized the accuracy of phagebased assays for the detection of rifampicin resistance (28). This meta-analysis showed that when performed on culture isolates, phage assays seem to have relatively high sensitivity and specificity. Eleven of 19 (58\%) studies included in the review reported sensitivity and specificity estimates of $95 \%$ or greater. Specificity estimates were slightly lower and more variable than sensitivity; 5 of $19(26 \%)$ studies reported specificity of less than $90 \%$. In only two studies were phage assays performed directly on sputum specimens, and the results were inconsistent. Current evidence, therefore, is restricted to the use of phage assays for the detection of rifampin resistance in culture isolates. When applied to isolates, these assays have relatively high sensitivity and specificity. However, the requirement for primary culture isolation reduces the applicability of this assay and increases turnaround time. Data are lacking on the accuracy of these assays when they are directly applied to sputum specimens. When applied directly to clinical specimens, phage assays seem to have lower sensitivity, presumably because of the lower bacillary concentration (27). If phage-based assays can be directly used on clinical specimens and if they are shown to be accurate, they have the potential to improve the diagnosis of drug-resistant TB (28). Efforts are ongoing to improve their performance characteristics, especially for the rapid direct detection of rifampicin resistance in clinical specimens (29). Preliminary results on improved direct phage assays show promise but require further validation and field testing (30).

\section{NEWER APPROACHES TO TREATMENT}

There have been several advances in the approach to treatment of LTBI and TB. First, the philosophy of caring for patients with TB has shifted in that the responsibility for completion and successful outcome now lies on the healthcare provider rather than the patient. Second, the duration of treatment in the continuation phase has been extended in select situations. Third, there are new agents available that show promise in the treatment of active TB that are being evaluated in clinical trials.

\section{Philosophy of Care: Provider Responsibility}

The main interventions to prevent the spread of TB are the detection of patients with infectious TB and providing them with effective treatment to ensure a rapid and lasting cure. Consequently, treatment for TB is not only a matter of individual health, such as is provided by, for example, treatment of hypertension or diabetes mellitus; it is also a matter of public health. Thus, all providers, public and private, who undertake to treat a patient with TB must have the knowledge to prescribe a standard treatment regimen and the means to ensure adherence to the regimen until treatment is completed. This shift in the focus of responsibility for completion of treatment represents an important evolutionary change in the management of patients with TB. The latest American Thoracic Society, Centers for Disease Control and Prevention, and Infectious Diseases Society of America guidelines (31) and the International Standards for Tuberculosis Care, currently in development (32), assign the responsibility for successful treatment of TB to the public health program or private provider and not to the patient.

The treatment of patients with TB is most successful within a comprehensive framework that addresses clinical and social issues of relevance to the patient. Adherence to therapy in patients with TB is a major determinant of their outcomes. A variety of modalities have been used to improve adherence in TB treatment. Directly observed therapy (DOT), in which patients are observed to ingest each dose of anti-TB medication, is widely used in the United States and elsewhere. DOT has been the most studied and is the most validated in improving adherence and treatment completion (33). DOT without incentives has completion rates better than self-administered therapy (34). However, several studies, including a meta-analysis associated with a consensus statement by the Public Health Tuberculosis Guidelines Panel, showed that adding a comprehensive, 


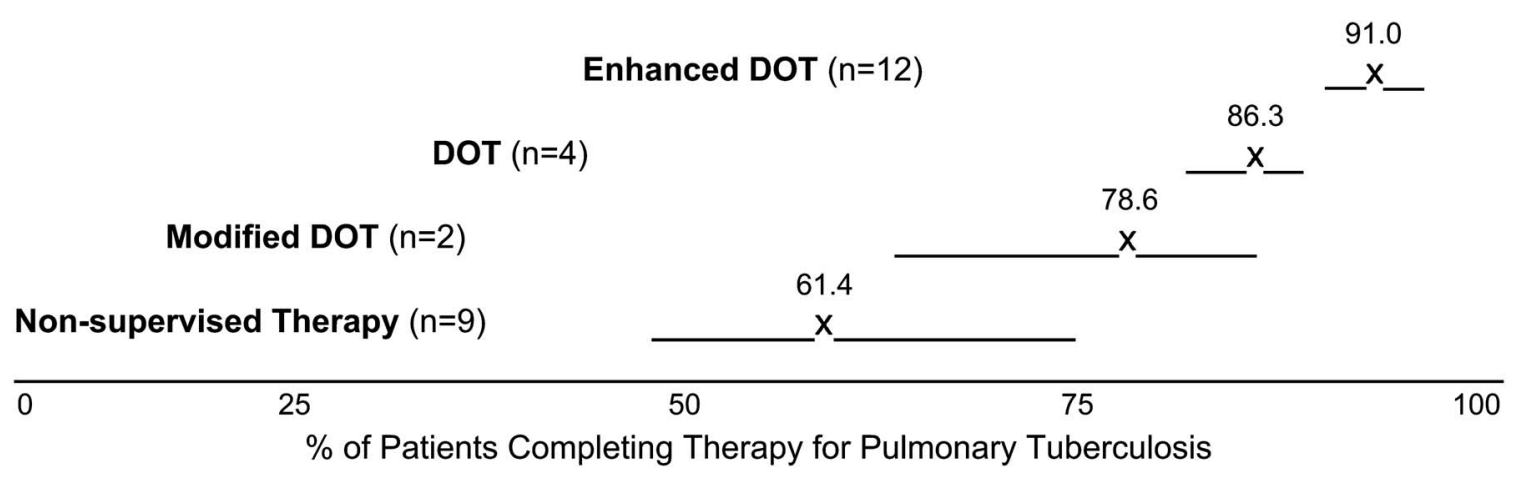

Figure 1. Range and median of treatment completion rates by treatment strategy for pulmonary TB reported in 27 studies. DOT $=$ see footnote at bottom of page; Enhanced DOT = individualized incentives and enablers were provided in addition to DOT; Modified DOT = supervision is used for only part of the treatment period, typically during the hospitalization phase of therapy, and thereafter patients are self-supervised; $\mathrm{n}=$ number of studies. Reprinted by permission from Reference 33.

patient-centered approach to case management to the DOT approach further improves adherence $(33,35)$. "Enhanced DOT," as defined by the use of a comprehensive set of incentives and enablers that are tailored to the target population within the context of DOT, show the highest completion rates, ranging from 86 to nearly $97 \%$ (Figure 1). Examples of incentives include food, clothing, housing, medical care, and outreach relevant to the target population. Adherence may be further improved by the use of intermittent dosing in the continuation phase of TB treatment, again tailored to the lifestyle of the patient. The initial treatment strategy used for new cases of TB should include patient-centered case management with an adherence plan that is agreeable to the patient and the provider (31).

Moreover, a recent analysis suggests that, because of the increasing amount of TB occurring among foreign-born persons in industrialized countries, expansion of a comprehensive case management program incorporating the internationally recommended expanded DOTS strategy* (Table 3) in high-burden

\section{TABLE 3. ELEMENTS OF THE EXPANDED DIRECTLY OBSERVED} THERAPY STRATEGY FOR TUBERCULOSIS CONTROL

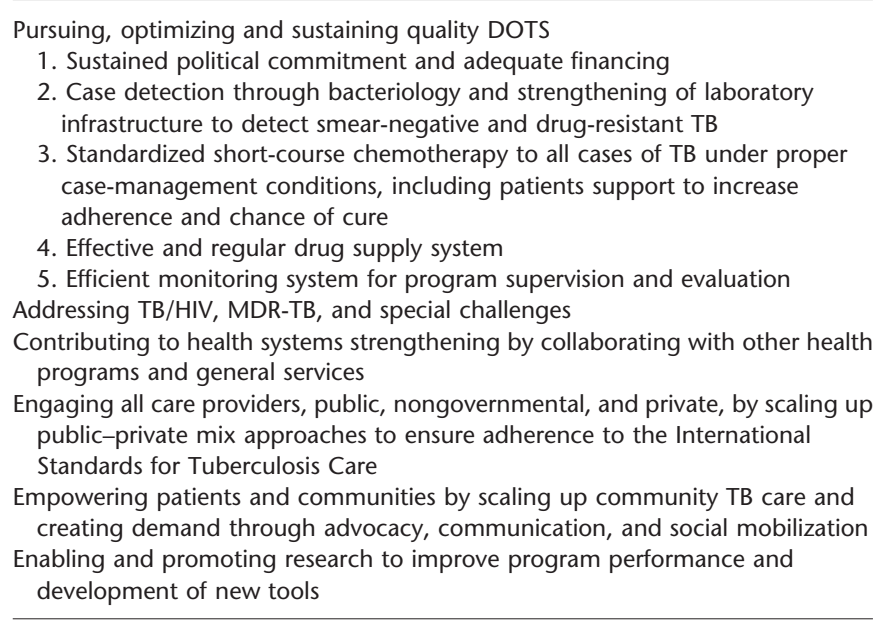

Definition of abbreviations: DOTS = directly observed therapy strategy; MDR = multidrug-resistant; TB = tuberculosis.

Adapted by permission from References 60 and 61 .

\footnotetext{
* The acronym, DOTS, originally stood for "directly observed therapy, short course," but in current usage it applies to the activities listed in Table 3.
}

countries funded by countries such as the United States and Canada would result in cost savings for these countries (36). The World Health Organization/International Union against Tuberculosis and Lung Disease global project on anti-TB drug resistance surveillance has also revealed that countries in which the majority of the population has access to the DOTS strategy have lower levels of drug resistance (37).

\section{Duration of Treatment: When Treatment Should Be Extended}

Extended treatment is recommended for patients with drugsusceptible pulmonary TB who have cavitation noted on the initial chest film and who have positive sputum cultures at the completion of 2 mo of treatment. This recommendation is based upon the findings of clinical trials that showed that these clinical markers were predictive of adverse outcomes such as treatment failure or relapse $(38,39)$. In the Tuberculosis Trials Consortium Study 22 , one in five patients with cavitation on initial chest radiograph and positive cultures at the end of the intensive phase of treatment relapsed versus 1 in 50 patients who had no evidence of cavitation on chest radiograph and converted their sputum cultures by the end of the second month of therapy (Table 4). As a consequence, sputum smears and cultures should be obtained after the intensive phase of treatment is completed to determine whether the continuation phase of treatment needs to be extended from the standard 4 to 7 mo. The majority of patients $(80 \%)$ with pulmonary TB caused by drug-susceptible organisms and treated with a standard four-drug, rifamycinbased regimen have negative sputum cultures at the end of the intensive phase of therapy.

Roles of Newer Agents: Rifabutin, Rifapentine, Fluoroquinolones

Rifamycins are the most important of the medications available for the treatment of TB (31). Unfortunately, rifampin and related

TABLE 4. PROPORTION OF CASES WHOSE TUBERCULOSIS RELAPSED BY THE PRESENCE OF INDEPENDENT PREDICTORS FOR RELAPSE IN THE TUBERCULOSIS TRIALS CONSORTIUM STUDY 22

\begin{tabular}{lcc}
\hline & \multicolumn{2}{c}{ Culture Positive at 2 mo of Therapy } \\
\cline { 2 - 3 } Risk Factors for Relapse & Yes & No \\
\hline Cavity on initial chest radiograph & & \\
Yes & $21.8 \%$ & $6.2 \%$ \\
No & $5.0 \%$ & $2.1 \%$ \\
\hline
\end{tabular}

Adapted by permission from Reference 38 . 


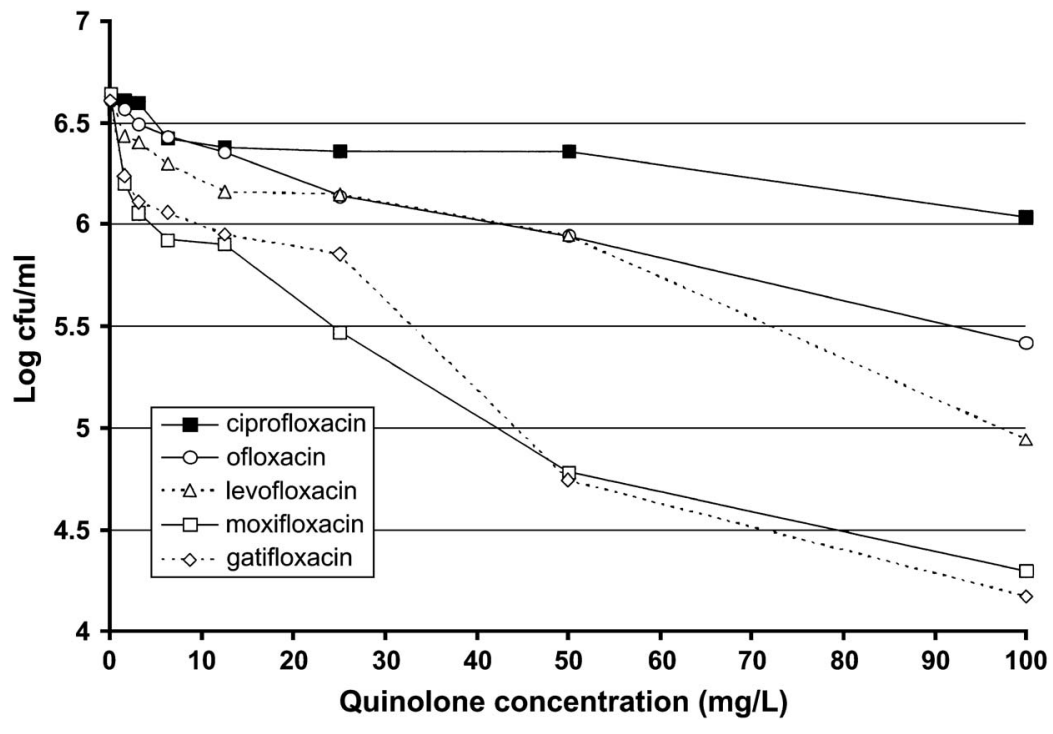

Figure 2. Viable counts after exposure of $100-\mathrm{d}$ cultures of $M$. tuberculosis to various concentrations of quinolones. Reprinted by permission from Reference 53 . rifamycins are also potent inducers of the cytochrome P-450 CYP3A oxidative enzymes. This characteristic can complicate their use (40). Rifabutin, a rifamycin spiropiperidyl derivative, has excellent minimal inhibitory concentrations (MICs) for rifamycin-susceptible isolates of $M$. tuberculosis and has the distinct advantage of inducing CYP3A enzymes the least as compared with rifampin and rifapentine (41). Thus, rifabutin has been shown to be useful in the management of patients who are HIV infected and are being treated with highly active antiretroviral therapy, particularly in those treated with a protease inhibitor. However, rifabutin reduces serum concentrations of many antiretroviral agents, although less so than rifampin (42). The achievable serum and tissue levels of rifabutin are well in excess of the MICs for rifampin-susceptible strains. However, intermittent dosing of rifabutin for active TB in HIV-infected patients has led to unacceptably high relapse rates and/or treatment failure commonly with acquired rifamycin resistant isolates $(43,44)$. Therefore, current guidelines state that HIV-infected patients with CD4 cell counts less than $100 / \mathrm{mm}^{3}$ should not be treated with highly intermittent (i.e., once- or twice-weekly) regimens and instead should receive daily therapy during the intensive phase and daily or three doses a week during the continuation phase (43). Adverse effects unique to rifabutin are uveitis and cytopenias; thus, patients should be monitored closely for the development of rifabutin toxicity $(45,46)$. If toxicity develops, rifabutin therapy should be discontinued promptly.

Rifapentine is a long-acting rifamycin with a half-life of approximately $12 \mathrm{~h}$ in patients and has excellent activity against M. tuberculosis in vitro (47). Rifapentine has been shown to be useful administered with INH in a once-weekly continuation phase. However, there are important contraindications to this regimen: cavitation on chest film, a sputum sample that is positive for acid-fast bacilli by smear at 2 mo of therapy, and the presence of HIV infection (31). When used in patients with these features, rates of relapse are unacceptably high $(38,48,49)$. The adverse effects of rifapentine are similar to those associated with rifampin. Rifapentine is an inducer of the P-450 hepatic enzymes and therefore may increase metabolism of coadministered drugs that are metabolized by these enzymes.

Fluoroquinolones have been used sporadically since the late 1980s primarily for the treatment of TB caused by resistant organisms or because of intolerance to first-line anti-TB therapy (50). The efficacy of this class of antimicrobials has been mostly determined from small retrospective studies $(51,52)$. More recently, fluoroquinolones have been under study as potential firstline agents. Of the fluoroquinolones, moxifloxacin and gatifloxacin are believed to have the most activity in vitro against M. tuberculosis, followed by levofloxacin and ofloxacin (Figure 2) (53, 54). Moxifloxacin seems to have the best MICs for M. tuberculosis (55). Although ofloxacin and levofloxacin have been used successfully in the treatment of multidrug resistant isolates of $M$. tuberculosis (52), the use of ciprofloxacin in drugsensitive TB has resulted in the increased risk of relapse and prolonged time to cure when substituted into first-line regimens (56). Thus, ciprofloxacin is not recommended as an equivalent first-line drug substitution (57). Data from several small trials confirm long-term safety and tolerability of fluoroquinolones as a class of antimicrobials (56). However, cross-resistance has been demonstrated among ciprofloxacin, ofloxacin, and levofloxacin and presumably is a class effect $(58,59)$. Until there are data from the Tuberculosis Trials Consortium studies evaluating the role of moxifloxacin in the initial intensive phase of treatment for patients with active TB as a substitute for ethambutol or isoniazid, fluoroquinolones should not be considered first-line agents for the treatment of drug-susceptible TB except in patients who are intolerant of or have isolates with drug resistance to first-line drugs.

Conflict of Interest Statement: None of the authors have a financial relationship with a commercial entity that has an interest in the subject of this manuscript.

\section{References}

1. Brennan MJ. The tuberculosis vaccine challenge. Tuberculosis (Edinb) 2005;85:7-12.

2. O'Brien RJ, Spigelman M. New drugs for tuberculosis: current status and future prospects. Clin Chest Med 2005;26:327-340, vii.

3. Perkins MD. New diagnostic tools for tuberculosis. Int J Tuberc Lung Dis 2000;4(Suppl 2)S182-S188.

4. Jasmer RM, Nahid P, Hopewell PC. Clinical practice: latent tuberculosis infection. N Engl J Med 2002;347:1860-1866.

5. Pai M, Riley LW, Colford JM Jr. Interferon-gamma assays in the immunodiagnosis of tuberculosis: a systematic review. Lancet Infect Dis 2004; 4:761-776.

6. Dheda K, Udwadia ZF, Huggett JF, Johnson MA, Rook GA. Utility of the antigen-specific interferon-gamma assay for the management of tuberculosis. Curr Opin Pulm Med 2005;11:195-202.

7. Pai M. Alternatives to the tuberculin skin test: Interferon-gamma assays in the diagnosis of mycobacterium tuberculosis infection. Indian J Med Microbiol 2005;23:151-158. 
8. Lalvani A. Spotting latent infection: the path to better tuberculosis control. Thorax 2003;58:916-918.

9. Brodie D, Schluger NW. The diagnosis of tuberculosis. Clin Chest Med 2005;26:247-271, vi.

10. Whalen CC. Diagnosis of latent tuberculosis infection: measure for measure. JAMA 2005;293:2785-2787.

11. Ferrara G, Losi M, Meacci M, Meccugni B, Piro R, Roversi P, Bergamini BM, D'Amico R, Marchegiano P, Rumpianesi F, et al. Routine hospital use of a new commercial whole blood interferon-gamma assay for the diagnosis of tuberculosis infection. Am J Respir Crit Care Med 2005;172:631-635.

12. Pai M, Lewinsohn DM. Interferon- $\gamma$ assays for tuberculosis: is anergy the Achilles' heel? Am J Respir Crit Care Med 2005;172:519-521.

13. Doherty TM, Demissie A, Olobo J, Wolday D, Britton S, Eguale T, Ravn $\mathrm{P}$, Andersen P. Immune responses to the Mycobacterium tuberculosisspecific antigen ESAT-6 signal subclinical infection among contacts of tuberculosis patients. J Clin Microbiol 2002;40:704-706.

14. Pai M. The accuracy and reliability of nucleic acid amplification tests in the diagnosis of tuberculosis. Natl Med J India 2004;17:233-236.

15. American Thoracic Society. Rapid diagnostic tests for tuberculosis: what is the appropriate use? American Thoracic Society Workshop. Am J Respir Crit Care Med 1997;155:1804-1814.

16. Flores LL, Pai M, Colford JM Jr, Riley LW. In-house nucleic acid amplification tests for the detection of Mycobacterium tuberculosis in sputum specimens: meta-analysis and meta-regression. BMC Microbiol 2005; 5:55.

17. Pai M, Flores LL, Hubbard A, Riley LW, Colford JM Jr. Nucleic acid amplification tests in the diagnosis of tuberculous pleuritis: a systematic review and meta-analysis. BMC Infect Dis 2004;4:6.

18. Pai M, Flores LL, Pai N, Hubbard A, Riley LW, Colford JM Jr. Diagnostic accuracy of nucleic acid amplification tests for tuberculous meningitis: a systematic review and meta-analysis. Lancet Infect Dis 2003;3:633-643.

19. Piersimoni C, Scarparo C. Relevance of commercial amplification methods for direct detection of Mycobacterium tuberculosis complex in clinical samples. J Clin Microbiol 2003;41:5355-5365.

20. Sarmiento OL, Weigle KA, Alexander J, Weber DJ, Miller WC. Assessment by meta-analysis of PCR for diagnosis of smear-negative pulmonary tuberculosis. J Clin Microbiol 2003;41:3233-3240.

21. El-Hajj HH, Marras SA, Tyagi S, Kramer FR, Alland D. Detection of rifampin resistance in Mycobacterium tuberculosis in a single tube with molecular beacons. J Clin Microbiol 2001;39:4131-4137.

22. Lin SYG, Probert W, Lo M, Desmond E. Rapid detection of isoniazid and rifampin resistance mutations in Mycobacterium tuberculosis complex from cultures or smear-positive sputa by use of molecular beacons. J Clin Microbiol 2004;42:4204-4208.

23. Piatek AS, Telenti A, Murray MR, El-Hajj H, Jacobs WR Jr, Kramer FR, Alland D. Genotypic analysis of Mycobacterium tuberculosis in two distinct populations using molecular beacons: implications for rapid susceptibility testing. Antimicrob Agents Chemother 2000;44: 103-110.

24. Varma-Basil M, El-Hajj H, Colangeli R, Hazbon MH, Kumar S, Bose M, Bobadilla-del-Valle M, Garcia LG, Hernandez A, Kramer FR, et al. Rapid detection of rifampin resistance in Mycobacterium tuberculosis isolates from India and Mexico by a molecular beacon assay. J Clin Microbiol 2004;42:5512-5516.

25. Morgan M, Kalantri S, Flores L, Pai M. A commercial line probe assay for the rapid detection of rifampicin resistance in Mycobacterium tuberculosis: a systematic review and meta-analysis. BMC Infect Dis 2005;5:62.

26. Hillemann D, Weizenegger M, Kubica T, Richter E, Niemann S. Use of the genotype MTBDR assay for rapid detection of rifampin and isoniazid resistance in Mycobacterium tuberculosis complex isolates. J Clin Microbiol 2005;43:3699-3703.

27. Kalantri S, Pai M, Pascopella L, Riley L, Reingold A. Bacteriophagebased tests for the detection of Mycobacterium tuberculosis in clinical specimens: a systematic review and meta-analysis. BMC Infect Dis 2005;5:59.

28. Pai M, Kalantri S, Pascopella L, Riley LW, Reingold AL. Bacteriophagebased assays for the rapid detection of rifampicin resistance in Mycobacterium tuberculosis: a meta-analysis. J Infect 2005;51:175-187.

29. Mole RJ, Trollip AP, Seaman T, Abrahams C, Albert H. Improved contamination control using a new antimicrobial supplement developed for rapid phage-based rifampicin susceptibility testing. Int $J$ Tuberc Lung Dis 2005;9(Suppl 1):S271.

30. Guerra H, RojasG, Chauca J, Henostroza G, Seas C, Vasquez L, Saravia J, O'Brien R, Perkins M, Llanos L, Gotuzzo E. Evaluation of a phage amplification assay for detection of MDR-TB in smear-positive patients in Lima, Peru (preliminary report). Int J Tuberc Lung Dis 2005;9(Supp 1):S196.

31. Blumberg HM, Burman WJ, Chaisson RE, Daley CL, Etkind SC, Friedman LN, Fujiwara P, Grzemska M, Hopewell PC, Iseman MD, et al. American Thoracic Society/Centers for Disease Control and Prevention/Infectious Diseases Society of America: treatment of tuberculosis. Am J Respir Crit Care Med 2003;167:603-662.

32. Hopewell PC, Pai M. Tuberculosis, vulnerability, and access to quality care. JAMA 2005;293:2790-2793.

33. Chaulk CP, Kazandjian VA. Directly observed therapy for treatment completion of pulmonary tuberculosis: Consensus Statement of the Public Health Tuberculosis Guidelines Panel. JAMA 1998;279:943948.

34. Jasmer RM, Seaman CB, Gonzalez LC, Kawamura LM, Osmond DH, Daley CL. Tuberculosis treatment outcomes: directly observed therapy compared with self-administered therapy. Am J Respir Crit Care Med 2004;170:561-566.

35. Davidson H, Schluger NW, Feldman PH, Valentine DP, Telzak EE, Laufer FN. The effects of increasing incentives on adherence to tuberculosis directly observed therapy. Int J Tuberc Lung Dis 2000;4:860865.

36. Schwartzman K, Oxlade O, Barr RG, Grimard F, Acosta I, Baez J, Ferreira E, Melgen RE, Morose W, Salgado AC, et al. Domestic returns from investment in the control of tuberculosis in other countries. N Engl J Med 2005;353:1008-1020.

37. World Health Organization. Anti-tuberculosis drug resistance in the world. Third Report. The WHO/IUATLD project on anti-tuberculosis drug resistance surveillance. Geneva: World Health Organization; 2004.

38. Benator D, Bhattacharya M, Bozeman L, Burman W, Cantazaro A, Chaisson R, Gordin F, Horsburgh CR, Horton J, Khan A, et al. Rifapentine and isoniazid once a week versus rifampicin and isoniazid twice a week for treatment of drug-susceptible pulmonary tuberculosis in HIV-negative patients: a randomised clinical trial. Lancet 2002;360: $528-534$.

39. Chang KC, Leung CC, Yew WW, Ho SC, Tam CM. A nested casecontrol study on treatment-related risk factors for early relapse of tuberculosis. Am J Respir Crit Care Med 2004;170:1124-1130.

40. Peloquin CA. Therapeutic drug monitoring in the treatment of tuberculosis. Drugs 2002;62:2169-2183.

41. Burman WJ, Gallicano K, Peloquin C. Comparative pharmacokinetics and pharmacodynamics of the rifamycin antibacterials. Clin Pharmacokinet 2001;40:327-341.

42. Burman WJ, Gallicano K, Peloquin C. Therapeutic implications of drug interactions in the treatment of human immunodeficiency virus-related tuberculosis. Clin Infect Dis 1999;28:419-29 (quiz: 430).

43. Centers for Disease Control and Prevention. Acquired rifamycin resistance in persons with advanced HIV disease being treated for active tuberculosis with intermittent rifamycin-based regimens. MMWR Morb Mortal Wkly Rep 2002;51:214-215.

44. Burman W, Benator D, Vernon A, Khan A, Jones B, Silva C, Lahart C, Weis S, King B, Mangura B, Weiner M, El-Sadr W. Acquired rifamycin-resistance with twice-weekly treatment of HIV-related tuberculosis. Am J Respir Crit Care Med 2006;173:350-356.

45. Tseng AL, Walmsley SL. Rifabutin-associated uveitis. Ann Pharmacother 1995;29:1149-1155.

46. Apseloff G, Fluids G, LaBoy-Goral L, Kraut E, Vincent J. Severe neutropenia caused by recommended prophylactic doses of rifabutin. Lancet 1996;348:685.

47. Weiner M, Bock N, Peloquin CA, Burman WJ, Khan A, Vernon A, Zhao Z, Weis S, Sterling TR, Hayden K, et al. Pharmacokinetics of rifapentine at 600,900 , and 1,200 $\mathrm{mg}$ during once-weekly tuberculosis therapy. Am J Respir Crit Care Med 2004;169:1191-1197.

48. Tam CM, Chan SL, Lam CW, Leung CC, Kam KM, Morris JS, Mitchison DA. Rifapentine and isoniazid in the continuation phase of treating pulmonary tuberculosis: initial report. Am J Respir Crit Care Med 1998;157:1726-1733.

49. Vernon A, Burman W, Benator D, Khan A, Bozeman L. Acquired rifamycin monoresistance in patients with HIV-related tuberculosis treated with once-weekly rifapentine and isoniazid. Tuberculosis Trials Consortium. Lancet 1999;353:1843-1847.

50. Ginsburg AS, Grosset JH, Bishai WR. Fluoroquinolones, tuberculosis, and resistance. Lancet Infect Dis 2003;3:432-442.

51. Chan ED, Laurel V, Strand MJ, Chan JF, Huynh ML, Goble M, Iseman MD. Treatment and outcome analysis of 205 patients with multidrugresistant tuberculosis. Am J Respir Crit Care Med 2004;169:1103-1109. 
52. Yew WW, Chan CK, Leung CC, Chau CH, Tam CM, Wong PC, Lee J. Comparative roles of levofloxacin and ofloxacin in the treatment of multidrug-resistant tuberculosis: preliminary results of a retrospective study from Hong Kong. Chest 2003;124:1476-1481.

53. Hu Y, Coates AR, Mitchison DA. Sterilizing activities of fluoroquinolones against rifampin-tolerant populations of Mycobacterium tuberculosis. Antimicrob Agents Chemother 2003;47:653-657.

54. Sulochana S, Rahman F, Paramasivan CN. In vitro activity of fluoroquinolones against Mycobacterium tuberculosis. J Chemother 2005;17: 169-173.

55. Rodriguez JC, Cebrian L, Lopez M, Ruiz M, Jimenez I, Royo G. Mutant prevention concentration: comparison of fluoroquinolones and linezolid with Mycobacterium tuberculosis. J Antimicrob Chemother 2004;53:441-444.

56. Ziganshina LE, Vizel A, Squire S. Fluoroquinolones for treating tuberculosis. Cochrane Database Syst Rev 2005;3:CD004795.
57. O'Brien RJ, Nunn PP. Ciprofloxacin is not a component of first-line TB. Chest 1994;106:1312.

58. Alangaden GJ, Manavathu EK, Vakulenko SB, Zvonok NM, Lerner SA. Characterization of fluoroquinolone-resistant mutant strains of Mycobacterium tuberculosis selected in the laboratory and isolated from patients. Antimicrob Agents Chemother 1995;39:1700-1703.

59. Huang TS, Kunin CM, Shin-Jung Lee S, Chen YS, Tu HZ, Liu YC. Trends in fluoroquinolone resistance of Mycobacterium tuberculosis complex in a Taiwanese medical centre: 1995-2003. J Antimicrob Chemother 2005;56:1058-1062.

60. World Health Organization. An expanded DOTS framework for effective tuberculosis control. Int J Tuberc Lung Dis 2002;6:378-388.

61. Stop TB Partnership and World Health Organization. DOTS expansion working group strategic plan 2006-2015, for the 2nd Global Plan to Stop TB. Available from: http:/www.stoptb.org/gpstb/assets/ wgstrategicplans/DEWGfull210905.pdf (accessed November 15, 2005). 